\title{
Matrix Metalloproteinase 3 Measurement
}

National Cancer Institute

\section{Source}

National Cancer Institute. Matrix Metalloproteinase 3 Measurement. NCI Thesaurus. Code C80194.

The determination of the amount of matrix metalloproteinase 3 present in a sample. 